\title{
On the Cooling Process of Nanofluid in a Square Enclosure with Linear Temperature Distribution on Left Wall
}

\author{
A. A. Abbasian Arani ${ }^{1}$, M. Mahmoodi ${ }^{1,2, \dagger}$, S. Mazrouei Sebdani ${ }^{1}$ \\ ${ }^{1}$ Department of Mechanical Engineering, University of Kashan, Kashan, Iran \\ ${ }^{2}$ Department of Mechanical Engineering, Amirkabir University of Technology, Tehran, Iran \\ ${ }^{\dagger}$ Corresponding Author Email: mmahmoodi46@gmail.com
}

(Received June 5, 2013; accepted December 18, 2013)

\begin{abstract}
In the present paper the problem of natural convection of $\mathrm{Al}_{2} \mathrm{O}_{3}$-water nanofluid with consideration of variable properties inside a square cavity with different linear temperature distribution on the left wall is investigated numerically. Effects of variations of Rayleigh number, temperature distributions, and volume fraction of nanoparticles on flow and temperature field and rate of heat transfer are studied. The obtained results show that as the temperature distribution on the left wall varies, the flow and temperature patterns inside the cavity vary too. Moreover the existence of the nanoparticles in the base fluid enhances or reduces the average Nusselt number depending on the Rayleigh number and value of the nanoparticles concentration. It is found that at convection dominated regime $\left(R a=10^{5}\right.$ and $\left.10^{6}\right)$, high values of nanoparticles volume fraction motivated the rate of heat transfer to decreases. When the lower end of left wall is cooled and its temperature increases by moving toward the top, a higher Nusselt number is obtained.
\end{abstract}

Keywords: Natural convection, Cavity, Nanofluid, Temperature Dependent, Linear heating.

\section{NOMENCLATURE}

$\begin{array}{ll}C_{p} & \text { specific heat, } \mathrm{J} \cdot \mathrm{Kg}^{-1} \cdot \mathrm{K}^{-1} \\ d & \text { diameter, } \mathrm{m} \\ g & \text { gravitational acceleration, } \mathrm{m} \cdot \mathrm{s}^{-2} \\ h & \text { heat transfer coefficient, } \mathrm{W} \cdot \mathrm{m}^{-2} \cdot \mathrm{K} \\ H & \text { enclosure height, } \mathrm{m} \\ k & \text { thermal conductivity, } \mathrm{W} \cdot \mathrm{m}^{-1} \cdot \mathrm{K}^{-1} \\ M & \text { molecular weight } \\ N & \text { Avogadro number } \\ N u & \text { average Nusselt number } \\ N u_{l} & \text { local Nusselt number } \\ P & \text { dimensionless pressure } \\ P r & \text { Prandtl number } \\ q & \text { heat flux, W.m-2 } \\ R a & \text { Rayleigh number } \\ R e & \text { Reynolds number } \\ w & \text { wall } \\ T & \text { temperature, } \mathrm{K}\end{array}$

\section{INTRODUCTION}

Natural convection in cavities is a prototype of many industrial applications such as ventilation of buildings, solar collectors and boilers. A comprehensive review of natural convection problems can be found in work by Ostrach (1988).

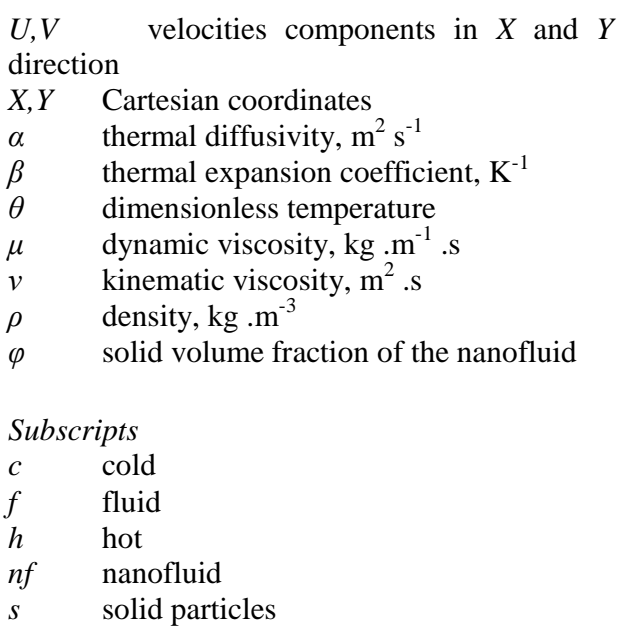

In buoyancy-driven flow in confined cavities thermal

and velocity boundary layers exist next to the walls while a core region is enclosed by the boundary 
layers. In majority of cases more than one primary core region is formed and secondary cells and cores are embedded in the primary core. The interactions between the boundary layers and cores motivate complexity in the problem. Natural convection in rectangular cavities with cold and hot side walls and insulated horizontal wall has been comprehensively studied by many authors. In actual and applied cases such as solar energy collection and cooling of electronic components the thermally active walls may be subject to non-uniform distribution of temperature due to shading or other effects in the fields. Hence, study on Natural convection in cavities with non-uniform temperature distribution on the walls is important in such situations. Free convection in a rectangular cavity with sinusoidal temperature profile on the upper wall and adiabatic conditions on the bottom and sidewalls has been investigated by Sarris et al. (2002). Numerical results of a study on steady laminar natural convection flow in a square cavity with uniformly and non-uniformly heated bottom wall, and adiabatic top wall has been reported by Basak et al. (2006). Natural convection in a cavity with heating and cooling by sinusoidal temperature profiles on one side was studied by Bilgen and Yedder (2007). Deng and Chang (2008) conducted a study on natural convection in a rectangular cavity with sinusoidal temperature distributions on both side walls and insulated horizontal walls.

Recently the nanofluids, which have a higher thermal conductivity compared to the base fluid, are used to enhance the rate of heat transfer (Ramiar et al. 2013). The enhanced heat transfer using the nanofluids are examined in the researches (Ghasemi and Razavi 2013, and Rashad et al. 2012). There are a number of studies on natural convection of a nanofluid in enclosures. Khanafer et al. (2003) investigated numerically Natural convection of nanofluid in rectangular cavities with cold right wall, hot left wall and insulated horizontal walls. Abu-nada and Oztop (2009) investigated effect of inclination angle of a square cavity on free convection of $\mathrm{Cu}$-water nanofluid inside it. Natural convection of water-based nanofluids in an inclined square cavity with a constant heat flux heater at the center of its left wall was studied numerically by Ögüt (2009). Results of a study on periodic free convection heat transfer inside a nanofluid filled square cavity were reported by Ghasemi and Aminossadati (2010). Results of a study on Natural convection of the $\mathrm{TiO}_{2}$-water nanofluid in rectangular cavities differentially heated on adjacent walls were reported by Sheikhzadeh et al. (2011).

In spite of a large number of studies about free convection of air in cavities with non-uniformly heated wall, there is a serious lack of information about natural convection of nanofluids in nonisothermal cavities. Oztop et al. (2011) investigated numerically Natural convection of $\mathrm{TiO}_{2}$-water and $\mathrm{Al}_{2} \mathrm{O}_{3}$-water nanofluids in an inclined enclosure with sinusoidal temperature profiles on left wall, cold right wall and adiabatic horizontal walls. Basak and Chamkha (2012) in a numerical study investigated natural convection of nanofluids in square cavity with differentially heated side walls and sinusoidal heating on the bottom wall. Very recently Oztop et al. (2012) have been used heatline visualization technique in their numerical study on natural convection $\mathrm{CuO}$-water nanofluid in an inclined non-uniformly heated enclosure. In the works by Oztop et al. $(2011,2012)$ and Basak et al. (2012), traditional equations were used to estimate thermal conductivity and viscosity of nanofluids, while Abu-nada et al. (2010) showed that these traditional equations do not calculate thermophysical properties of nanofluid properly. Aim of the current study is to investigate the problem of natural convection of a nanofluid with variable properties in square cavity with different linear temperature distributions on side wall. Effects of increase in the buoyancy force, volume fraction of nanoparticles, and distributions of temperature on the wall are investigated.

\section{PROBLEM STATEMENT}

A view of the square cavity considered in the present study is shown in Fig. 1. The height and width of the cavity are identical and denoted by $H$. The horizontal walls of the cavity are insulated while its right wall is kept at cold temperature, $T_{c}$. Two different temperature distributions are subjected to the left walls which form two different cases. For these cases the maximum temperature of the left wall is hot temperature of $T_{h}$. The $\mathrm{Al}_{2} \mathrm{O}_{3}$ water nanofluid is considered as coolant. Table 1 shows the thermophysical properties of the $\mathrm{Al}_{2} \mathrm{O}_{3}$ nanoparticles and pure water at $T=25{ }^{\circ} \mathrm{C}$. The nanofluid is considered Newtonian and incompressible and the flow is studied in laminar regime $\left(R a \leq 10^{6}\right)$. The Boussinesq approximation is considered for density variation. The conservation of mass, momentum and energy equations for twodimensional laminar natural convection in nondimensional form are:

$$
\begin{aligned}
& \frac{\partial U}{\partial X}+\frac{\partial V}{\partial Y}=0 \\
& U \frac{\partial U}{\partial X}+V \frac{\partial U}{\partial Y}=-\frac{\partial P}{\partial X}+\frac{\operatorname{Pr} \rho_{f}}{\rho_{n f}}\left(\frac{\partial^{2} U}{\partial X^{2}}+\frac{\partial^{2} U}{\partial Y^{2}}\right) \\
& U \frac{\partial V}{\partial X}+V \frac{\partial V}{\partial Y}=-\frac{\partial P}{\partial Y}+\frac{\operatorname{Pr} \rho_{f}}{\rho_{n f}}\left(\frac{\partial^{2} V}{\partial X^{2}}+\frac{\partial^{2} V}{\partial Y^{2}}\right) \\
& +\operatorname{RaPr} \frac{(\rho \beta)_{n f}}{\rho_{n f} \beta_{f}} \theta \\
& U \frac{\partial \theta}{\partial X}+V \frac{\partial \theta}{\partial Y}=\frac{\alpha_{n f}}{\alpha_{f}}\left(\frac{\partial^{2} \theta}{\partial X^{2}}+\frac{\partial^{2} \theta}{\partial Y^{2}}\right)
\end{aligned}
$$

The following dimensionless parameters are used in the above equations: 

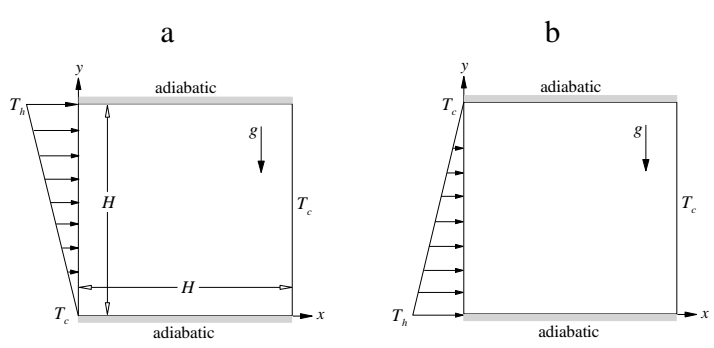

Fig. 1. A square cavity with cold right wall and four different temperature distributions on the left wall, (a) case \# 1, (b) case \# 2.

Table 1 Thermophysical properties of water and the nanoparticles (Oztop et al. 2011).

\begin{tabular}{|c|c|c|}
\hline $\begin{array}{l}\text { Physical } \\
\text { properties }\end{array}$ & Water & $\mathrm{Al}_{2} \mathrm{O}_{3}$ \\
\hline$C_{p}(\mathrm{~J} / \mathrm{kg} \mathrm{K})$ & 4179 & 765 \\
\hline$\rho \quad\left(\mathrm{kg} / \mathrm{m}^{3}\right)$ & 997.1 & 3970 \\
\hline$k \quad(W / m K)$ & 0.613 & 40 \\
\hline$\beta \quad\left(K^{-1}\right)$ & $21 \times 10^{-5}$ & $0.85 \times 10^{-5}$ \\
\hline$\mu \quad(\mathrm{kg} / \mathrm{ms})$ & $10.03 \times 10^{-4}$ & $=$ \\
\hline
\end{tabular}

$X=\frac{X}{H}, Y=\frac{y}{H}, U=\frac{u H}{\alpha_{f}}, V=\frac{v H}{\alpha_{f}}, P=\frac{p H^{2}}{\rho_{n f} \alpha_{f}^{2}}$,

$\theta=\frac{T-T_{c}}{T_{h}-T_{c}}$

In the above equations the Rayleigh number, $R a$, and the Prandtl number, $P r$, are:

$$
R a=\frac{g \beta_{f_{o}}\left(T_{h}-T_{c}\right) H^{3}}{\alpha_{f_{o}} v_{f_{o}}}, \operatorname{Pr}=\frac{v_{f_{o}}}{\alpha_{f_{o}}}
$$

the subscript "o" refers to the reference temperature which is $25^{\circ} \mathrm{C}$. The following formulas are used to calculate the density, heat capacity, thermal expansion coefficient, and thermal diffusivity of the nanofluid, respectively (Abu-nada and Oztop, 2009):

$$
\begin{aligned}
& \rho_{n f}=(1-\varphi) \rho_{f}+\varphi \rho_{s} \\
& \left(\rho c_{p}\right)_{n f}=(1-\varphi)\left(\rho c_{p}\right)_{f}+\varphi\left(\rho c_{p}\right)_{s} \\
& (\rho \beta)_{n f}=(1-\varphi)(\rho \beta)_{f}+\varphi(\rho \beta)_{s} \\
& \alpha_{n f}=k_{n f} /\left(\rho c_{p}\right)_{n f}
\end{aligned}
$$

The effective thermal conductivity of the nanofluid is estimated by the empirical correlation reported by Corcione (2011) which includes temperature and particle size effects and is expressed as follows:

$$
\frac{k_{n f}}{k_{f}}=1+4.4 \varphi^{\frac{66}{100}}\left(\frac{T}{T_{f r}}\right)^{10}\left(\frac{k_{s}}{k_{f}}\right)^{\frac{3}{100}} \operatorname{Pr}^{\frac{66}{100}} \operatorname{Re}^{0.4}
$$

where $T$ is the nanofluid temperature, $T_{f r}$ is the freezing point of the base liquid, $k_{s}$ is the nanoparticle thermal conductivity, $P r$ is the Prandtl number of the base liquid, and $R e$ is the nanoparticle Reynolds number and defined as (Corcione 2011):

$$
R e=\frac{2 \rho_{f} k_{b} T}{\pi \mu_{f}^{2} d_{s}}
$$

where the symbol $\mathrm{kb}$ is the Boltzmann constant $\left(k_{b}=1.3807 \times 10^{-23} \mathrm{~J} / \mathrm{K}\right)$. The effective dynamic viscosity of the nanofluid is calculated by the empirical correlation proposed by Corcione (2011):

$$
\frac{\mu_{n f}}{\mu_{f}}=\frac{1}{1-34.87\left(\frac{d_{s}}{d_{f}}\right)^{-0.3} \varphi^{1.03}}
$$

where $d_{f}$ is the equivalent diameter of base fluid molecules and given by:

$d_{f}=0.1\left(\frac{6 M}{N \pi \rho_{f 0}}\right)^{\frac{1}{3}}$

in which $M$ is the molecular weight of the base fluid, $N$ is the Avogadro number, and $\rho_{f o}$ is the mass density of the base fluid calculated at temperature $T_{0}=293 \mathrm{~K}$. The dimensionless boundary conditions are:

$$
\begin{aligned}
& X=1: U=V=0, \theta=0 \\
& Y=0: \quad U=V=0, \partial \theta / \partial Y=0 \\
& \{=1: U=V=0, \partial \theta / \partial Y=0 \\
& X=0:\left\{\begin{array}{l}
\text { case\# } 1: U=V=0, \theta=X \\
\text { case \#2: } U=V=0, \theta=1-X
\end{array}\right.
\end{aligned}
$$

The local Nusselt number along the vertical walls of the cavity and based on its height is evaluated from the following formula:

$$
N u_{l}=\frac{h_{n f} H}{k_{f}},
$$

The heat transfer coefficient, $h_{n f}$, is obtained from

$$
\begin{aligned}
& h_{n f}=\frac{q}{\left(T_{h}-T_{c}\right)}, \\
& q=-\left.k_{n f} \frac{\left(T_{h}-T_{c}\right)}{H} \frac{\partial \theta}{\partial X}\right|_{X=0 \text { or } X=1} .
\end{aligned}
$$

Substituting Eqs. (17) and (18) into Eq. (16) yields:

$$
N u_{l}=-\left.\frac{k_{n f}}{k_{f}} \frac{\partial \theta}{\partial X}\right|_{X=0 \text { or } X=1} .
$$

The average Nusselt number along the right and left wall is obtained by integrating Eq. (19) along the right and left wall, respectively.

\section{NUMERICAL METHODS}

The above governing equations have been discretized by finite volume method based on a staggered grid. The diffusion terms are discretized by a second-order central difference approximation while a hybrid scheme which is a combination of upwind and central difference schemes is employed for discretization of the convective terms. The 
pressure and velocity fields are coupled by utilizing SIMPELER algorithm (Patankar 1980). The set of discretized equations were solved by the tridiagonal matrix algorithm (TDMA) while relaxation factors were used to ensure convergence of the discretized equations. The convergence criterion is defined by the following relation:

$$
\text { Error }=\frac{\sum_{j=1}^{m} \sum_{i=1}^{n}\left|\eta^{t+1}-\eta^{t}\right|}{\sum_{j=1}^{m} \sum_{i=1}^{n}\left|\eta^{t+1}\right|} \leq 10^{-7}
$$

In the above equation $\mathrm{m}$ and $\mathrm{n}$ are the number of grid pointes in the $x$ and $y$ direction, respectively, $\eta$ is a computational quantity, and $t$ is number of iteration.

To ensure grid independent numerical results, a square cavity with boundary conditions according to the case \# 1, filled with the $\mathrm{Al}_{2} \mathrm{O}_{3}$-water nanofluid at $R a=10^{5}$ is considered and the numerical results for five different uniform grid sizes, namely, $41 \times 41,61 \times 61,81 \times 81,101 \times 101$, and $121 \times 121$, are obtained. These results are presented in Fig. 2. As can be observed, an $81 \times 81$ grid size is sufficiently fine for accurate numerical simulation.
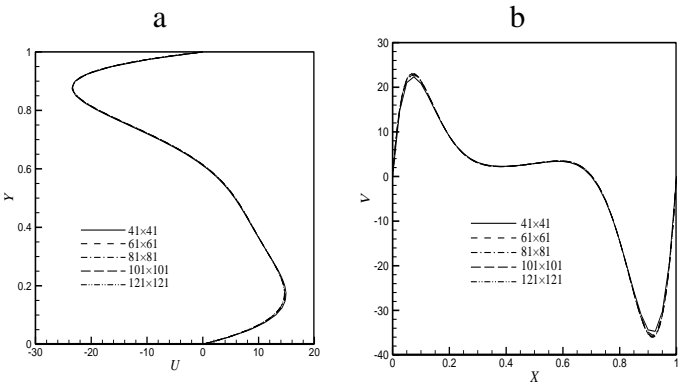

Fig. 2. Grid independence study for case \# 1 with $\varphi=0.04$ at $R a=10^{5}$, (a) $U$ along $X=0.5$, (b) $V$ along $Y=0.5$.

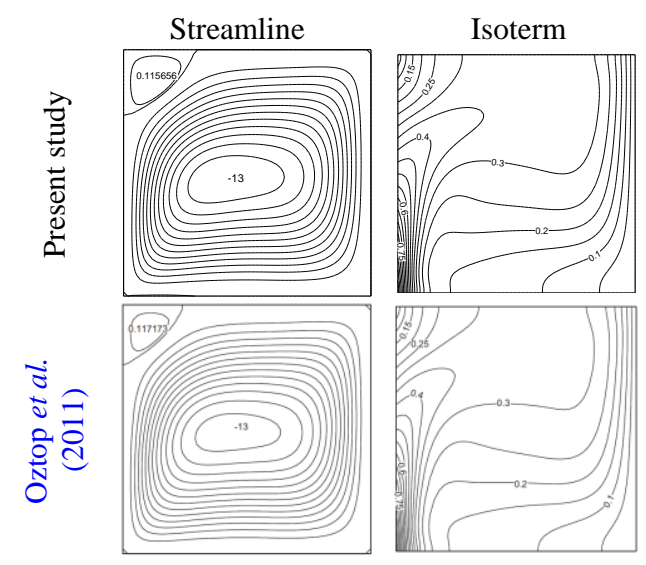

Fig. 3. Comparison between the results obtained by the present code and those obtained by Oztop et al. (2011), $\left(R a=10^{5}, \varphi=0.02\right)$.

The code testing is conducted by comparing the results obtained by the present code with those obtained by Oztop et al. (2011). This problem is free convection of $\mathrm{Al}_{2} \mathrm{O}_{3}$-water nanofluid in a square cavity with insulated horizontal walls, cold right wall and sinusoidal heated left wall. The obtained results are presented in Fig. 3. As it is observed from the figure a good agreement exists between these results.

\section{RESULTS AND DISCUSSIONS}

In the present section, the results of numerical simulation of natural convection $\mathrm{Al}_{2} \mathrm{O}_{3}$-water, with consideration of variable properties, in square cavities shown in Fig. 1 are presented. These results are provided for the Rayleigh number ranging from $10^{3}$ to $10^{6}$, the volume fraction of the nanoparticles ranging from 0 to 0.06 , and two different temperature distributions on the left wall.

Variations of streamlines and isotherms with Rayleigh number and volume fraction of the nanoparticles for the cavity of case \#1 are shown in Fig. 4. In this case the lower end of the left wall is kept at temperature of $T_{c}$ and by moving upward along the wall its temperature increases. As it is expected, the cold fluid in the lower left corner of the cavity is heated along the left wall and moves to the top of this wall, then moves horizontally to the cold wall and is cooled and descends. This cycle forms a clockwise primary eddy which occupies major portion of the cavity. At low Rayleigh number $\left(R a=10^{3}\right.$ and $\left.10^{4}\right)$, which the fluid flow in not very strong, the core of the eddy is circularshaped and is located at the middle of the cavity. As the Rayleigh number increases and subsequently convection becomes stronger, the flow strength increases and the core of the eddy moves next to the right wall. It is obvious that the convection of the fluid becomes more important and the nanofluid tends to move in upper portion of the cavity, hence the core of eddy moves upward. At $R a=10^{6}$ the condensation of streamlines in the upper portion of cavity is more than that in lower portion

It is characteristic of high velocity of fluid in the upper half of the cavity. As can be seen in the figure the existence of the nanoparticles in the base fluid motivates the flow intensity to decrease while the flow pattern does not change significantly. The decrease is due to higher viscosity of the nanofluid compared to the pure fluid.

At $R a=10^{3}$ and $10^{4}$ the isotherms are uniformly distributed in the cavity which is characteristic of conduction dominated heat transfer. Moreover because of domination of conduction heat transfer the increase in volume fraction of the nanoparticles does not change the temperature distribution in the cavity significantly. As Rayleigh number increases to $10^{5}$, the characteristics of natural convection heat transfer appear. At this Rayleigh number the isotherms are condensed adjacent the side wall which shows formation of thermal boundary layer. At $R a=10^{6}$ convection becomes stronger and formation of the thermal boundary layer becomes more apparent. At convection dominated regime $\left(R a=10^{5}\right.$ and $\left.10^{6}\right)$ via existence of suspended nanoparticles in the base fluid, which increases thermal conductivity, the thermal boundary layers thicken.. Figure 5 illustrates streamlines and isotherms at different Rayleigh numbers and 
volume fraction of the nanoparticles inside the cavity of case \# 2. In this case the lower end of the left wall is kept at $T_{h}$ and its temperature decreases linearly from down to the top of the wall. The cold fluid living the cold right wall moves horizontally and faces the left hot wall, then is heated and moves upward along this wall. As the heated nanofluid ascends, the wall temperature decreases and the effect of buoyancy force decreases. At $R a=10^{3}$ a primary large eddy occupies major portion of the cavity which its core is located at the center of the cavity filled both pure fluid and nanofluid. At $R a=$ $10^{4}$, when the cavity is filled with pure fluid, a secondary small eddy is formed in upper left corner of the cavity via friction losses and stagnation pressure. When the cavity is filled with nanofluid the secondary eddy disappears. It is because of higher viscosity of nanofluid which increases diffusion of momentum.

$$
\varphi=0
$$
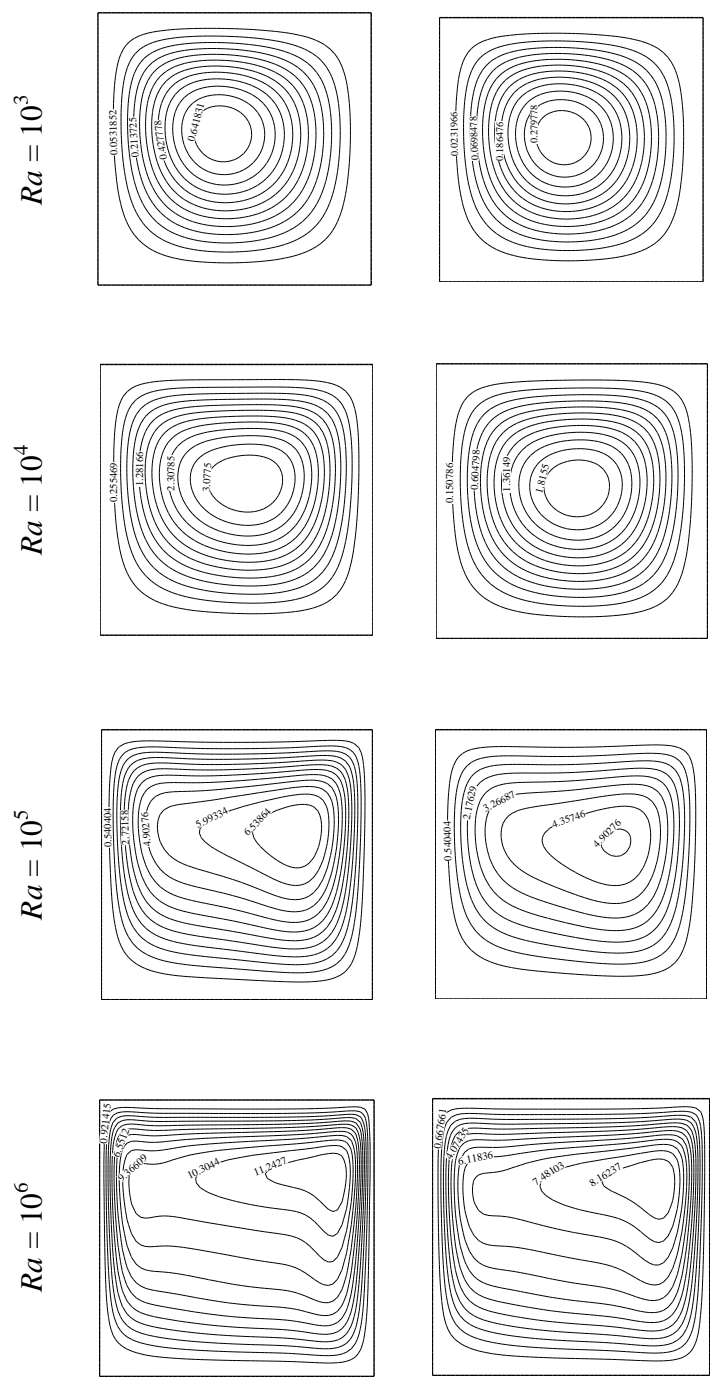

Streamlines

$$
\varphi=0
$$$$
\varphi=0.06
$$
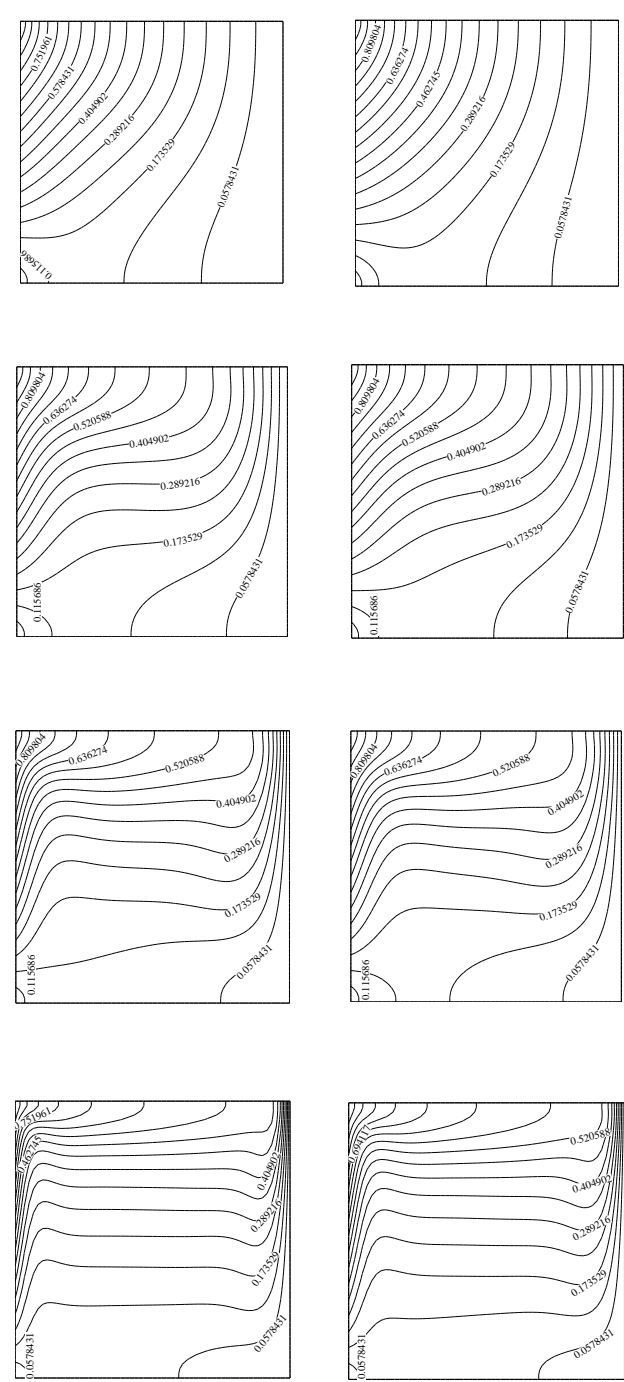

Isotherms

Fig. 4. Streamlines and isotherms inside the cavity of case \# 1 at different Rayleigh numbers for pure fluid $(\varphi=0)$ and nanofluid $(\varphi=0.06)$ 
A. A. Abbasian Arani et al. / JAFM, Vol.7, No. 4, pp. 591-601, 2014.

$$
\varphi=0
$$

$\varphi=0.06$

$\varphi=0$

$\varphi=0.06$
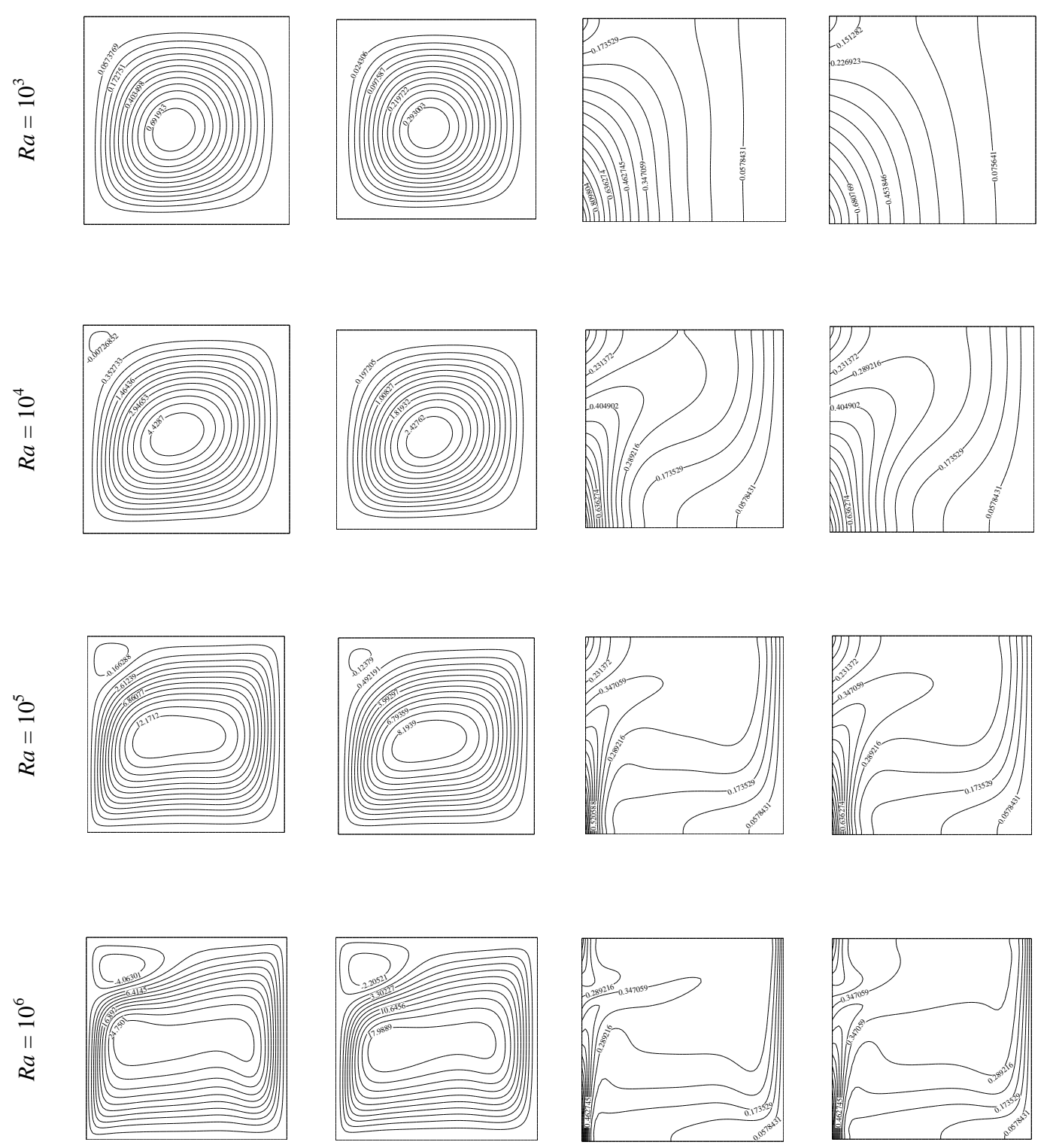

Streamlines

Isotherms

Fig. 5. Streamlines and isotherms inside the cavity of case \# 2 at different Rayleigh numbers for pure fluid $(\varphi=0)$ and nanofluid $(\varphi=0.06)$ 
A. A. Abbasian Arani et al. / JAFM, Vol.7, No. 4, pp. 591-601, 2014.
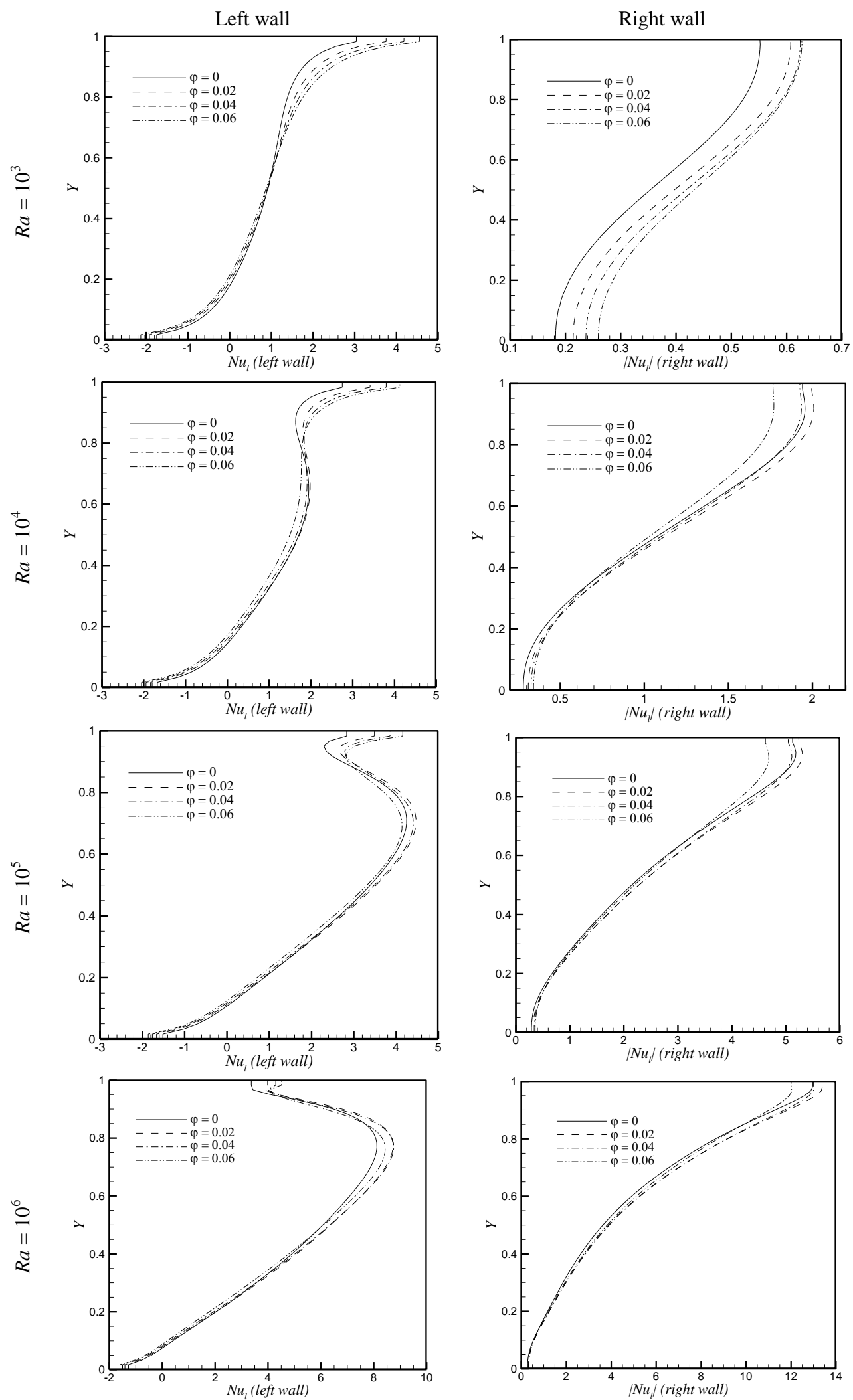

Fig. 6. Variation of the local Nusselt number along the left and right walls of the cavity versus Rayleigh number and volume fraction of the nanoparticles for the cavity of case \# 1 . 
A. A. Abbasian Arani et al. / JAFM, Vol. 7, No. 4, pp. 591-601, 2014.
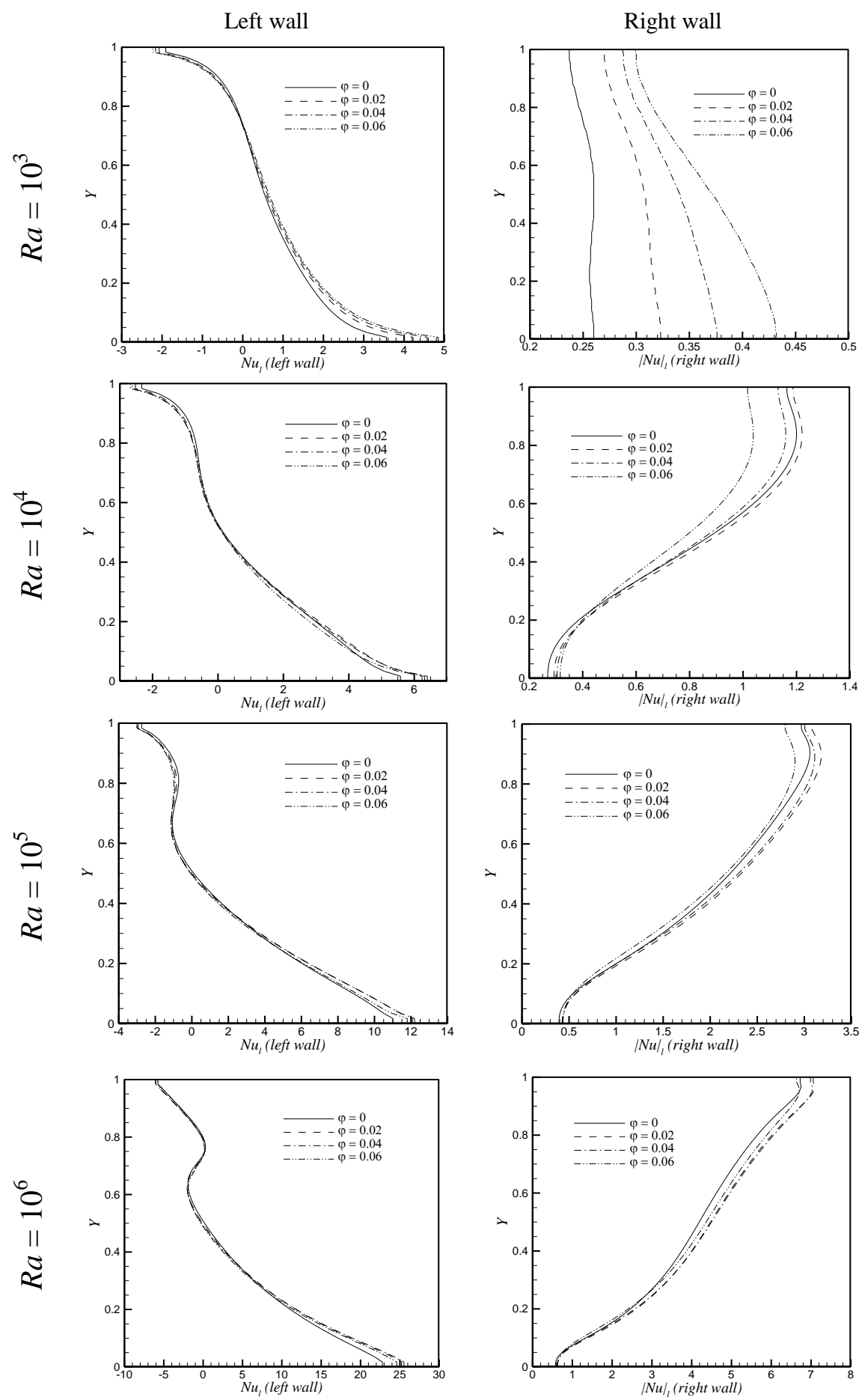

Fig. 7. Variation of the local Nusselt number along the left and right walls of the cavity versus Rayleigh number and volume fraction of the nanoparticles for the cavity of case \# 2 . 
At $R a=10^{5}$ and $10^{6}$ the length of the region with negative Nusselt number decreases compared to lower Rayleigh numbers. At $0.1 \leq Y \leq 0.3$ the existence of the nanoparticles in the base fluid deteriorates the heat transfer. For the larger values of $Y$ the volume fraction of the nanoparticles up to 0.04 increases the rate of heat transfer while by further increases in $\varphi$ reduces the local Nusselt number

Now the Nusselt number distributions on the right wall of the cavity of case \# 1 are considered. The hot fluid leaving the left wall which moves horizontally faces the top of the cold right wall and the maximum temperature gradient occurs in this region, where maximum local Nusselt number is obtained. By moving downward along the wall the fluid becomes colder, the temperature gradient decreases and rate of heat transfer decreases. From view point of the existence of the nanoparticles in the base fluid it can be said that at all considered Rayleigh numbers the increase in $\varphi$ from 0 up to 0.04 enhances the rate of heat transfer in all regions of the right wall, while for $\varphi=0.06$ the heat transfer is deteriorated with the exception of $R a=10^{3}$. At $R a=10^{3}$ (nearly purely conduction dominated heat transfer regime) the high viscosity of the nanofluid for $\varphi=0.06$ does not decrease the heat transfer, while by increasing the buoyancy force at higher values of $R a$, the high viscosity reduces the flow strength which motivated the total rate of heat transfer to decrease.

Nusselt number distributions at different Rayleigh numbers and for different values of volume fraction of the nanoparticles along the left and right walls of the cavity of case \# 2 are depicted in Fig. 7. At $R a=10^{3}$ two distinct regions are observed along the left wall. For $Y \geq 0.8$ the values of local Nusselt number are negative. At $Y \leq 0.8$ the values of local Nusselt number are positive. The cold fluid leaving the cold right wall faces the lower hot end of the left wall and the high temperature gradient in this region motivates maximum local Nusselt number. Moreover it is observed that in both two regions the existence of the nanoparticles in the base fluid increases the local rate of heat transfer. At $R a=10^{4}$ the Nusselt number distribution is similar to that at $R a=10^{3}$. The difference is that at $R a=10^{4}$ the point of zero Nusselt number is located at $Y=0.6$. At higher Rayleigh numbers $\left(R a=10^{5}\right.$ and $\left.10^{6}\right)$ a local variation in Nusselt number distribution is observed at $Y \geq 0.6$ which is due to the existence of the secondary small eddy in this region (Fig. 5).

In Fig. 8 the effects of $R a, \varphi$, and temperature distribution along the left wall on total rate of heat transfer are presented. In calculation of the average Nusselt number along the left wall, the hot portion of the wall, in which the heat is transferred from the wall to the fluid, is considered. At all Rayleigh numbers, maximum Nusselt number is related to the case \# 2. In case \# 1, cold fluid leaving the cold wall faces the lower cold end of the left wall; hence minimum temperature gradient exists for this case. Also the blockage effect of the top wall reduces the heat transfer from the top end of the left wall, which is a hot region. Therefore minimum rate of heat transfer occurs for this case. In case \# 2, cold fluid leaving the cold right wall faces the lower hot end of the left wall; hence maximum temperature gradient occurs for this case which motivates maximum Nusselt number.

At $R a=10^{3}$ the rate of heat transfer increases with increase in volume fraction of the nanoparticles. At this Rayleigh number the heat transfer occurs nearly through conduction and the high viscosity of the nanofluid does not reduce the rate of heat transfer. At higher Rayleigh numbers the increase in $\varphi$ from 0 to 0.03 enhances the rate of heat transfer, while further increase in $\varphi$ reduces the rate of heat transfer. For $\varphi \geq 0.03$ the reduction of convection heat transfer due to high viscosity of the nanofluid has higher effect compared to the increasing conduction heat transfer via high thermal conductivity of the nanoparticles, hence the total rate of heat transfer decreases.

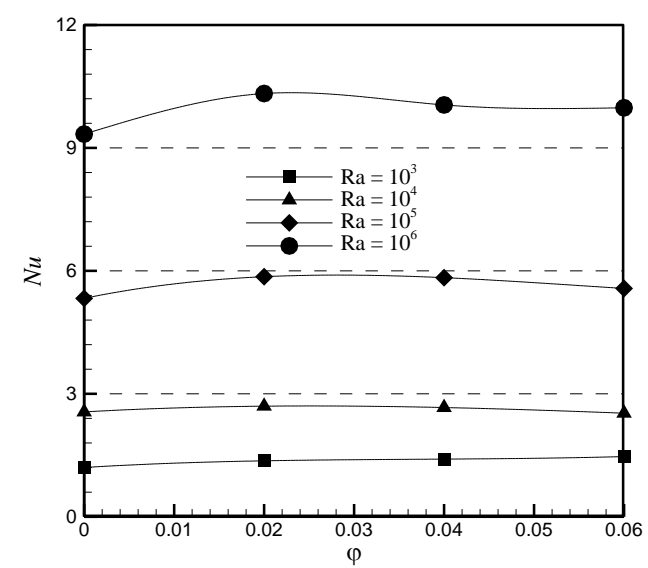

(a)

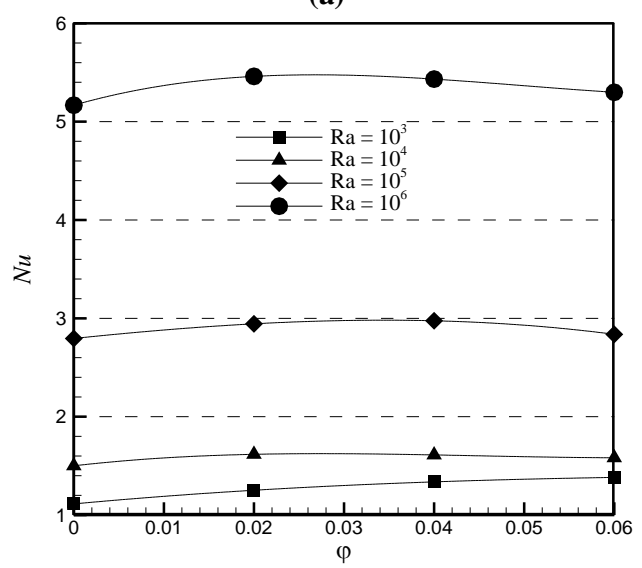

(b)

Fig. 8. Variation of the average Nusselt number of the left and right walls of the cavity versus volume fraction of the nanoparticles at different Rayleigh numbers and for all considered cases, (a) case \# 1, (b) case \# 2.

\section{CONCLUSION}

Using the finite volume method, the problem of natural convection cooling of a nanofluid in a 
square cavity with insulated horizontal wall, cold right wall, and differently linearly heated left wall was studied. Effects of some pertinent parameters such as Rayleigh number, different linear temperature distributions, and the volume fraction of the nanoparticles on the fluid flow and heat transfer characteristics were investigated and the following results were obtained.

- Flow pattern and temperature distributions inside the cavity vary significantly for with different temperature distributions on the left wall.

- The flow intensity of the nanofluid is lower than that of the base fluid because of higher viscosity of the nanofluid compared to the base fluid.

- Apart from total rate of heat transfer, in different zones along the left wall the local Nusselt number for the cavity filled with the nanofluid can be higher or lower of that of the cavity filled with base fluid. It mainly depends on Rayleigh number and temperature distribution along the left wall.

- For two considered cases and at $R a=10^{3}, 10^{5}$, and $10^{6}$ for low values of volume fraction of the nanoparticles local Nusselt number increases via existence of nanoparticles, while at $R a=10^{4}$ the existence of the nanoparticles in the base fluid motivates the local Nusselt number to decreases.

- At $R a=10^{3}$ the average Nusselt number increase with increase in volume fraction of the nanoparticles

- for all values of $\varphi$. At $\mathrm{Ra}=104$ the average Nusselt number decreases via existence of the nanoparticles in the base fluid. At $\mathrm{Ra}=105$ and 106, the average Nusselt number increase with increase in $\varphi$ up to 0.03 . For higher values of $\varphi$ the high viscosity of the nanofluid reduces the flow velocity along the side wall and weakens the natural convection, hence the average Nusselt number decreases.

- Case \# 2, in which the lower end of the left wall is kept at $\mathrm{Tc}$, has higher heat transfer rate compared to case \# 1

\section{REFERENCES}

Abu-nada, E. and H. Oztop, (2009). Effect of inclination angle on natural convection in enclosures filled with $\mathrm{Cu}$-Water nanofluid. Int . J. Heat Fluid Flow 30, 669-678.

Abu-nada, E., Masoud, Z., Oztop, H.F., and A. Campo, (2010). Effect of nanofluid variable properties on natural convection in enclosures. Int. J. Thermal Sci., 49, 479-491.

Basak, T., Roy, S. and A.R. Balakrishnan, (2006). Effects of thermal boundary conditions on natural convection flows within a square cavity. Int. J. Heat Mass Transfer 49, 45254535 .

Basak, T. and A. J. Chamkha (2012). Heatline analysis on natural convection for nanofluids confined within square cavities with various thermal boundary conditions. International
Journal of Heat and Mass Transfer 55, 55265543.

Bilgen, E. and R. B. Yedder, (2007). Natural convection in enclosure with heating and cooling by sinusoidal temperature profiles on one side. Int. J. Heat Mass Transfer 50, 139150.

Corcione, M. (2011). Empirical correlating equations for predicting the effective thermal conductivity and dynamic viscosity of nanofluids, Energy.Conversion and Management 52, 789-793.

Deng, Q. and J. Chang, (2008). Natural convection in a rectangular enclosure with sinusoidal temperature distributions on both side walls. Numerical Heat Transfer, Part A 54, 507-524.

Ghasemi, B. and S. M. Aminossadati, (2010). Periodic natural convection in a nanofluidfilled enclosure with oscillating heat flux. Int. J. Thermal Sci. 49, 1-9.

Ghasemi, J. and S. E. Razavi, (2013). Numerical Nanofluid Simulation with Finite Volume Lattice-Boltzmann Enhanced Approach, Journal of Applied Fluid Mechanics, 6, 519527.

Khanafer, K. Vafai, K. and M. Lightstone, (2003). Buoyancy-driven heat transfer enhancement in a two-dimensional enclosure utilizing nanofluid. Int. J. Heat Mass Tran. 46, 36393653.

Ögüt, E. B. (2009). Natural convection of Waterbased nanofluids in an inclined enclosure with a heat source. Int. J. Thermal Sci. 48, 20632073.

Ostrach, S. (1988). Natural convection in enclosures, ASME Trans. J. Heat Transfer 110, 1175-1190.

Oztop, H. F., Abu-Nada, E., Varol, Y. and Kh. AlSalem, (2011). Computational analysis of nonisothermal temperature distribution on natural convection in nanofluid filled enclosures. Superlattices and Microstructures 49, 453467.

Oztop, H. F., Mobedi, M., Abu-Nada, E. and I. Pop, (2012). A heatline analysis of natural convection in a square inclined enclosure filled with a $\mathrm{CuO}$ nanofluid under non-uniform wall heating condition. International Journal of Heat and Mass Transfer 55, 5076-5086.

Ramiar, A., Ranjbar, A. A., and S. F. Hosseinizadeh, (2012). Effect of Axial Conduction and Variable Properties on TwoDimensional Conjugate Heat Transfer of $\mathrm{Al}_{2} \mathrm{O}_{3}$-EG/Water Mixture Nanofluid in Microchannel, Journal of Applied Fluid 
A. A. Abbasian Arani et al. / JAFM, Vol.7, No. 4, pp. 591-601, 2014.

Mechanics 5, 79-87.

Rashad, A. M., Chamkha A. J. and M. M. M. Abdou, (2013). Mixed Convection Flow of Non-Newtonian Fluid from Vertical Surface Saturated in a Porous Medium Filled with a Nanofluid, Journal of Applied Fluid Mechanics, 6, 301-309.

Patankar, S. V. (1980) Numerical Heat transfer and fluid flow. Hemisphere Pub. Co. Washington. DC.
Sarris, I. E., Lekakis, I. and N. S. Vlachos, (2002). Natural convection in a $2 \mathrm{~d}$ enclosure with sinusoidal upper wall temperature. Numerical Heat Transfer, Part A 42, 513-530.

Sheikhzadeh, G. A., Arefmanesh, A. and M. Mahmoodi, (2011). Numerical Study of Natural Convection in a Differentially - Heated Rectangular Cavity Filled with $\mathrm{TiO}_{2}$-Water Nanofluid. Journal of Nano Research 13, 7580 . 